\title{
Are all Glioma Cells Cancer Stem Cells?
}

\author{
Cruz Mabel ${ }^{1}$, Siden Âke ${ }^{1,2}$, Tasat Deborah Ruth ${ }^{3}$ and Yakisich J. Sebastian ${ }^{1 *}$
}

${ }^{1}$ Department of Clinical Neuroscience R54, Karolinska Institute, Stockholm, Sweden

${ }^{2}$ Department of Neurology, Karolinska University Hospital, Stockholm, Sweden

${ }^{3}$ Universidad Nacional de San Martín Buenos Aires, Argentina

\begin{abstract}
The cancer stem cell theory proposes that there is a small but constant subpopulation of cancer cells with stem cell properties responsible for the self renewal capacity and unlimited proliferation of tumor as well as increased resistance to antineoplastic drugs. Targeting these cells might constitute an effective way to cure cancer. Regarding gliomas, by analysing proliferation kinetics of cultures containing mixed subpopulations and experimental data from literature on glioma cell lines, we propose a model (Stemness Phenotype Model) in which all glioma cells have stem cells properties but their phenotype varies depending on the environmental conditions. This model provides an alternative explanation to different and sometimes controversial experimental findings and might be a useful guide for future research in the field of gliomas and stem cell biology.
\end{abstract}

Keywords: Cancer; Glioma; Stem cells; Proliferation; Stem cell theory; Stemness

\section{Introduction}

Limitless replicative potential is one of the hallmarks of cancer cells and normal stem cells: while normal cells have limited replication capacity, stem cells and cancer cells can be propagated indefinitely (Hanahan and Weinberg, 2000; Rubin, 2002). Stem cells have also long-term self-renewal ability and capacity to give rise to one or more types of differentiated progeny (Nicolis, 2007). The existence of cancer stem cells was reported in several cancer cell lines (Setoguchi et al., 2004) suggesting that cancers are maintained by cancer stem cells making them an important therapeutic target. Increasing data support the existence of cancer stem cells in gliomas and several publications reported the existence of glioma stem cells (GSCs) in available glioma cell lines as well as in patient derived cell lines (Fukaya et al., 2010; Kondo et al., 2004; McCord et al., 2009; Qiang et al., 2009; Ropolo et al., 2009; Singh et al., 2004; Zheng et al., 2007; Zhou et al., 2009). In general, resistance of gliomas and other brain tumors to therapy and relapse after standard treatments is attributed to the presence of stem-like cells (Charles and Holland, 2010). Criteria for defining GSCs include properties such as multipotentiality, self-renewal, indefinite proliferation in vitro (Limitless Replicative Potential), and tumorigenicity in vivo. Regarding the percentage of glioma stem cells in cell lines, the data have been controversial. The best studied cell line is the glioma C6 cell line where authors reported values from 0.4 to $100 \%$ (Table 1 ). These marked differences can be attributed to technical procedures such as among others, isolation methods, cell culture conditions, stem cell markers (Table 1). Probably, the best experimental approach to define the percentage of GSCs in the C6 glioma cell line was the work published by Zheng et al. (2007) (Zheng et al., 2007), where isolated single cells were expanded as clonal lines and representative subclones evaluated for their ability to sustain tumor growth in mouse. In that study 67 out of 67 subclones were able to form a new tumor in mouse indicating that most (probably 100\%) of cells were cancer stem cells. The authors also proposed a model where stem cells always divided symmetrically (Figure 4 in Zheng et al. (2007)). Shen et al. (2008) found by means of a tumor sphere culture system and a single-cell subsphere generation assay that the majority C6 cells $(>80 \%)$ have stem cell properties (Shen et al., 2008) while analysis of stem cells markers and the "side population" showed that a small percentage of C6 cells has stem cell properties (Kondo et al., 2004; Zhou et al.,
2009). The current dogma in the cancer field is that cell lines contain at least two subpopulations of cells: cancer stem cells and non-cancer stem cells. Elucidating the real percentage of each subpopulation in cell lines and cancers in vivo is not only of academic interest but has also important implications for the development of new therapeutic modalities for cancer treatment.

\section{Are all glioma cells in cell lines stem cells?}

It is widely accepted that GSCs proliferate slower than non-GSCs and experimental data support this statement. A recent study showed that the average population doubling time (PDT) for non GSCs and GSCs is approximately $28-30 \mathrm{~h}$ and $55-60 \mathrm{~h}$ respectively (Ropolo et al., 2009). In order to bring together experimental data and the stem cell concept we analysed the theoretical possibility of coexistence of two different subpopulations in a same cell line. A simple mathematical analysis predicts that existing cells lines containing at least two subpopulations with different cell cycle length, when propagated for a high number of passages, should be enriched for the fastest dividing subpopulation initially present at the moment of isolation. Even small differences in the cell cycle length will produce a cell line enriched for the fastest subpopulation (Yakisich, 2009) . Since the C6 glioma cell line has been propagated thousands of times (Kondo et al., 2004) it is expected that the slowly proliferating stem cells subpopulations might have disappeared at some point. However, the C6 glioma cell line was apparently isolated and expanded from a single cell (Benda et al., 1968). Then, to explain the presence of GSCs and non-GSC in this cell line, the primordial C6 cell must have been a GSC that, by definition of SC, was able to originate non-GSCs (this assumption does not explain Zheng's experiment, see below). Other cell lines and patient derived cell lines were obtained by propagating mixed cell populations instead of single cells. Frequently cell biologists isolate cell lines from tumoral tissue. Therefore, in these cases, the primary

*Corresponding author: Yakisich J. Sebastian, Ph.D., Department of Clinical Neuroscience, Karolinska University Hospital, Stockholm, Sweden, Tel: +46 858589 533; Fax: +46 8585 83810; E-mail: Sebastian.Yakisich@ki.se

Received May 06, 2010; Accepted June 16, 2010; Published June 16, 2010

Citation: Cruz M, Siden Å, Tasat DR, Yakisich JS (2010)Are all Glioma Cells Cancer Stem Cells? J Cancer Sci Ther 2: 100-106. doi:10.4172/1948-5956.1000032

Copyright: @ 2010 Cruz M, et al. This is an open-access article distributed under the terms of the Creative Commons Attribution License, which permits unrestricted use, distribution, and reproduction in any medium, provided the original author and source are credited. 
Citation: Cruz M, Siden Å, Tasat DR, Yakisich JS (2010) Are all Glioma Cells Cancer Stem Cells? J Cancer Sci Ther 2: 100-106. doi:10.4172/19485956.1000032

\begin{tabular}{|c|c|c|c|}
\hline Cell Line & Percentage & Method & Reference \\
\hline C6 (rat) & $0.4 \%$ & Isolation of the SP fraction & (Kondo et al., 2004) \\
\hline C6 (rat) & $4.21 \%$ & Nestin-labelled flow cytometry & (Zhou et al., 2009) \\
\hline C6 (rat) & $86.5 \%$ & Tumor sphere culture, isolation by CD133 marker, SP analysis & (Shen et al., 2008) \\
\hline C6 (rat) & $\begin{array}{c}100 \% \\
1.52 \\
\end{array}$ & $\begin{array}{l}\text { Single cell isolation } \\
\text { SP fraction }\end{array}$ & $\begin{array}{l}\text { (Zheng et al., 2007) } \\
\text { (Qiang et al., 2009) } \\
\end{array}$ \\
\hline N29 (rat) & $\begin{array}{l}99.38 \% \\
99.92 \% \\
\end{array}$ & $\begin{array}{c}\text { CD133 }^{+} \text {Cells } \\
\text { Nestin-labelled flow cytometry }\end{array}$ & $\begin{array}{l}\text { (Bexell et al., 2009) } \\
\text { (Bexell et al., 2009) }\end{array}$ \\
\hline N32 (rat) & $\begin{array}{l}99.79 \% \\
99.76 \% \\
\end{array}$ & $\begin{array}{c}\text { CD133 }^{+} \text {Cells } \\
\text { Nestin-labelled flow cytometry }\end{array}$ & $\begin{array}{l}\text { (Bexell et al., 2009) } \\
\text { (Bexell et al., 2009) }\end{array}$ \\
\hline SK-MG-1 (human) & $2.8 \%$ & Isolation of the SP fraction & (Fukaya et al., 2010) \\
\hline U87MG (human) & $\begin{array}{c}0.7 \%, 1.34 \% \\
0.9 \%\end{array}$ & $\begin{array}{c}\text { Isolation of the SP fraction } \\
\text { Isolation of the SP fraction } \\
\text { CD } 133^{+} \text {Cells } \\
\end{array}$ & $\begin{array}{l}\text { (Fukaya et al., 2010) } \\
\text { (Chua et al., 2008) } \\
\text { (Qiang et al., 2009) }\end{array}$ \\
\hline U373MG (human) & $0.4 \%, 1.90 \%$ & $\begin{array}{l}\text { Isolation of the SP fraction } \\
\text { Isolation of the SP fraction }\end{array}$ & $\begin{array}{l}\text { (Fukaya et al., 2010) } \\
\text { (Chua et al., 2008) }\end{array}$ \\
\hline KNS42 (human) & $0.5 \%$ & Isolation of the SP fraction & (Fukaya et al., 2010) \\
\hline U251 (human) & $\begin{array}{c}0.1 \% \\
0.63 \% \\
3.2 \% \\
2.05 \% \\
\end{array}$ & $\begin{array}{l}\text { Isolation of the SP fraction } \\
\text { Isolation of the SP fraction } \\
\text { CD } 133^{+} \text {Cells } \\
\text { Isolation of the SP fraction }\end{array}$ & $\begin{array}{l}\text { (Fukaya et al., 2010) } \\
\text { (Qiang et al., 2009) } \\
\text { (Qiang et al., 2009) } \\
\text { (Chua et al., 2008) } \\
\end{array}$ \\
\hline T98 & $2.01 \%$ & Isolation of the SP fraction & (Chua et al., 2008) \\
\hline A172 & $\begin{array}{l}6.81 \% \\
2.1 \% \\
\end{array}$ & $\begin{array}{l}\text { Isolation of the SP fraction } \\
\text { CD133 } 13{ }^{+} \text {Cells }\end{array}$ & $\begin{array}{l}\text { (Chua et al., 2008) } \\
\text { (Qiang et al., 2009) }\end{array}$ \\
\hline
\end{tabular}

Table 1: Detection of GSCs in established glioma cell lines.

cell culture might contain different cell subpopulations with different proliferative kinetics. After continuous passages, the expected progressive enrichment of the fastest growing subpopulation opens, in the stem cells field, some controversial questions. It is likely that glioma cells lines after extensive passages should contain either pure non-GSCs (that proliferate fast) or pure GSCs (that proliferate slowly) but not both. Since several cell lines, as mentioned above, were isolated from expanding mixed tumors, it is expected that most of the cell lines should contain only non-GSCs (if they outgrow GSCs). The second possibility is that the expansion of the culture selected for stem cells because non-GSCs did not survive the procedure or they spontaneously stop dividing after they reach the Hayflick limit.

This theoretical analysis raises the following question: how can glioma cell lines maintain a constant but rare subpopulation of GSCs? The model proposed by Zheng et al. (2007) (Figure 4 therein) concludes that "a cell line cannot maintain a rare but constant fraction of stem cells unless the stem cells divide symmetrically"(Zheng et al., 2007). The model shows that when starting a culture containing 99 non-GSCs and 1 GSC (1\%), after four cell divisions the culture would contain 1564 non-GSC and 16 GSCs (1\%). This might be true only for non-GSCs and GSCs dividing at the same rate. Zheng's model assumes that stem and non stem cells have similar proliferation rates. When the slower PDT of GSCs is considered, this scenario changes completely and fails to reconciliate experimental data. Table 2 shows the expected outcome for the percentage of two different

\begin{tabular}{|c|c|c|c|c|c|}
\hline Time(h) & $\begin{array}{c}\text { Non-GSCs } \\
\text { (PDT 24h) }\end{array}$ & $\begin{array}{c}\text { GSCs } \\
\text { (PDT 24h) }\end{array}$ & Total (\%) & $\begin{array}{c}\text { GSCs } \\
\text { (PDT 36h) }\end{array}$ & Total (\%) \\
\hline 0 & 99 & 1 & $100(1 \%)$ & 1 & $100(1 \%)$ \\
\hline 12 & & & & & \\
\hline 24 & 198 & 2 & $200(1 \%)$ & & \\
\hline 36 & & & & 2 & \\
\hline 48 & 396 & 4 & $400(1 \%)$ & & \\
\hline 60 & & & & & \\
\hline 72 & 792 & 8 & $800(1 \%)$ & 4 & $796(0.50 \%)$ \\
\hline 84 & & & & & \\
\hline 96 & 1584 & 16 & $1600(1 \%)$ & & \\
\hline 108 & & & & 8 & \\
\hline 120 & 3168 & 32 & $3200(1 \%)$ & & \\
\hline 132 & & & & & \\
\hline 144 & 6336 & 64 & $6400(1 \%)$ & 16 & $6352(0.25 \%)$ \\
\hline
\end{tabular}

Table 2: Percentage of GSCs in a mixed culture compared to non-GSCs of similar (Blue) or longer PDT (Red) than the GSC subpopulation.
GSCs with PDTs (24h and 36h) present in a cell culture when starting at a ratio non-GSCs: GSC $=99: 1$ and compares it to non-GSC (PDT= 24h). It clearly shows that the slower proliferating cell subpopulation (PDT 36h) will gradually decrease and eventually disappear when co-incubated with a subpopulation of shorter PDT (24h). Using the same type of analysis showed in Table 2, a faster subpopulation (PDT $=18 \mathrm{~h}$ ) will undergo 8 divisions within $144 \mathrm{~h}$ and its percentage will increase up to $4 \%$. Undoubtedly, unless GSCs and nonGSCs have the same PDT, one cell subpopulation will sooner or later outgrow the other. Thus, it is unlikely that mixed non-GSCs and GSCs cultures will keep a constant but rare fraction of stem cells as the model based in independent cell subpopulations proposes.

\section{The symmetrical and asymmetrical cell division models}

Can the symmetrical or asymmetrical nature of cell division explain the experimental findings?

In symmetrically dividing cells (GSCs producing only GSCs and non-GSCs producing only non-GSCs), isolation of single cells will produce only pure GSCs clones and subclones or pure non-GSCs clones and subclones (Figure $1 \mathrm{~A}-\mathrm{B}$ ). To account for a small population of non-GSCs, one can assume that a fraction of GSCs "differentiate" producing non-GSCs (Figure 1B, box). In this case, it becomes a type of asymmetrical division after all. Once a non-GSC (that divides faster than the GSCs) is generated it will outgrow the GSC population and at the end the culture will become a pure non-GSC cell line. More important, this assumption does not explain Zheng's experiment where $100 \%$ of isolated cells had stem cell properties.

Asymmetrical division of non-GSCs is not possible by definition (Figure 1C). In the case that GSCs always divide asymmetrically rendering a GSC and a non-GSC, the clonal expansion of a single GSC will give a culture containing always 1 GSC and increasing number of non-GSC (Figure 1D). Of course, one can argue that in the asymmetrical cell division model, the unique GSC present in the culture might at some point divides symmetrically. (Figure 1D box). The only "advantage" of this model is that it will explain the presence of more than 1 GSC cell in the clonal line. Due to the initial high number of non-GSCs and the slower PDT of GSCs, it is expected that the clonal expansion of a single GSC cell will produce a culture composed mostly of non-GSCs. Once again, this model does 
Symmetrical

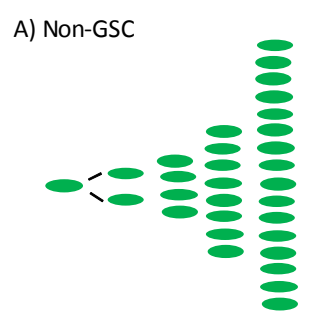

B) GSC

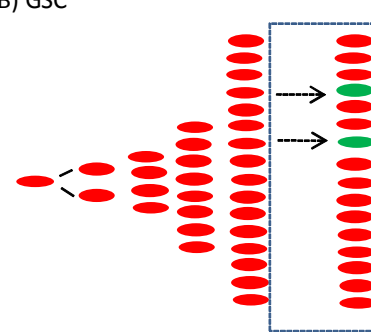

Asymmetrical

C) Non-GSC

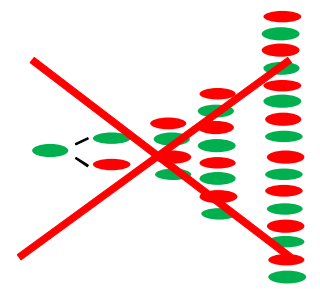

D) GSC

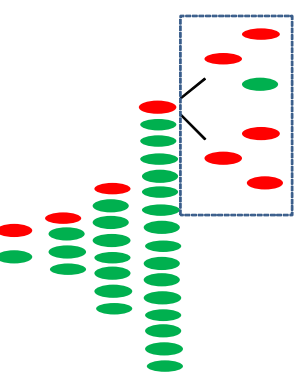

Figure 1: Predicted composition of a cell culture after expansion of a single cell according to the mode of cell division. (A) By symmetrical division a non-GSC (green oval) will produce a culture composed of only non-GSCs. (B) A GSC (red oval) will also produce only GSCs and, non-GSCs may arise only by differentiation of GSCs (box) resembling asymmetrical division. (C) Asymmetrical division of a non-GSC does not occur by definition. (D) Clonal expansion of a single GSC will produce a cell culture containing increasing number of non-GSC and only one GSC unless the GSC at some point divides symmetrically (box).

not explain why $100 \%$ of GSCs after single cell isolation have stem cell properties. In summary, both "symmetrical division" followed by differentiation of a certain fraction of GSCs into non-GSCs and "asymmetrical division" followed by symmetrical division in a fraction of GSC might explain the occurrence of a fraction of GSCs. To explain the constant percentage of GSCs, one should assume a very delicate balance between non-GSC generation (produced by symmetric division or differentiation), cell death and proliferation rate of the two subpopulations.

In 2007, Blagosklonny, in order to explain the constant fraction of stem cells, postulated the existence of "stemloids", defined basically as stem cells that proliferate fast (Blagosklonny, 2007). Again, to maintain a constant fraction of stem cells, "stemloids" must proliferate at the same rate as non-GSC otherwise, "stemloids" depending whether they proliferate slower or faster than non- GSCs will eventually either disappear from the cell culture or outgrow the non-GSCs rendering either a pure "stemloids" cell line or a pure nonGSCs cell line. In spite of these assumptions, none of the models explain Zheng's experiment because all of them predict the existence of non-GSCs that will generate clones without SC properties.

\section{The "stemness phenotype" model (SPM)}

The term "stemness" is by itself controversial (Leychkis et al., 2009). In this paper, in order to follow the criteria usually adopted to define cancer stem cells, we use the term "stemness" as the property of having the potential for limitless replication, selfrenewal, multilineage differentiation, and tumorigenicity. Any model regarding the stem cell presence in culture should explain at least 1) the variable percentage of GSCs in the C6 glioma cell line reported by several groups (Table 1), 2) Zheng's experiment, 3) the conserved tumorigenic property of the cell line over time that might be due to the persistence of at least a rare but constant fraction of GSCs in cell lines.

All the models discussed above assume that there are at least two different subpopulations (2 compartment models). The stemloid hypothesis proposes the existence of three subpopulations (nonGSCs, GSCs and stemloids). We propose a "1 compartment model" that we call "Stemness Phenotype Model, SPM" where there is only one cancer cell type. These cells are cells with different stemness phenotype due to random biological variation (Figure 2 I). In cultures having thousands to millions of cells, individual cells varies phenotypically (e.g. expression of stem cell markers, sensitivity to drugs, resistance to apoptosis) due to random variability giving rise to the apparent presence of different subpopulations (e.g. SP fraction, $\mathrm{CD}_{133^{+}}$fraction, drug resistant cells). The stemness depends on the environment where the cells grow and can range from a phenotype resembling a non-GSC to a pure GSC. A prediction of this model is that there are cells having "intermediate phenotypes" between both extremes. This seems to be the case since e.g., some CD133"-a nonGSC trait- cells have self renewal ability that is a GSC trait (Kelly et al., 2009). Thus, all cells have stem cell potential but they require a permissive environment to express specific traits. Moreover, these different phenotypes can interconvert into each other when permissive environmental changes occur (Figure 2 II). In 2006, Hill suggested that "it is very possible that, in cancer cells, degrees of stemness exist and that these are variably expressed depending on the environment to which the cells are exposed" (Hill, 2006 ). In agreement with Hill's conclusion, the SPM proposes that the culture condition modifies the stemness phenotype and dictates the apparent rate of GSCs/nonGSC phenotype. Our hypothesis expands Hill's conclusions based in theoretical analysis of proliferation kinetics of mixed populations (see above) and new experimental data generated later in several laboratories. At a constant culture condition (e.g. routine serum containing media) the majority of cells adopt a nonGSCs phenotype. Strictly speaking, not all cells in vitro grow under the same, constant culture conditions. For instance, incubation time changes the availability of nutrients and cells should adapt to these changes. In cultures favouring the GSC phenotype (e.g. Serum free + EGF + FGF) cells having a GSCs phenotype proliferate while other cells stop dividing and eventually die due to the harsh conditions. Cells adapt to the changing environment and drastic changes from one environment to another might trigger programmed cell death and only few cells might survive. For example, shifting from serum containing media to serum free media (or similar stem cell media) might be harmful for most cells with non-GSC phenotype. Milder environmental changes might shift the percentage of cells having one phenotype to another. In support of this "adaptation process", it was recently reported that the in vivo environment changed the selfrenewal capacity of C6 cells (Shen et al., 2008), and the expression of CD133 (Griguer et al., 2008; Qiang et al., 2009; Soeda et al., 2009).

Interestingly, it was reported that the human lung carcinoma cell line DLKP contains 3 distinct subpopulations. On prolonged cultures two of them can interconvert to the third one and the growth and attachment properties of the clones themselves varied under the different assay conditions (McBride et al., 1998). Due to the fact that they have different proliferation kinetics, it is likely that the three subpopulations are different phenotypes of the same cell and not true different subpopulations. Unfortunately, the presence of stem cells has not been studied in this cell line. However, the fact that in a cell line a subpopulation having a certain phenotype can interconvert to another phenotype is a strong argument favoring the interconversion among different cell phenotypes proposed by the SPM (Figure 2II). 
How does the SPM brings together experimental data in a single model? The SPM proposes that there are no true different subpopulations of GSCs and non-GSCs but a single cell type that can interconvert to each other depending on the environmental conditions. By doing so, GSCs don't need to be constantly generated in cell lines and explains why GSCs don't disappear even when a cell line (e.g. the C6 cell line) has been sub-cultivated thousands of times. Instead, the constant presence is explained by the ability of cancer cells to adopt different phenotypes according to the environment (e.g. different culture conditions and isolation methods used in experiments showed in Table 1). The same argument explains the conserved tumorigenic property of the C6 glioma cell line over time. The adaptation to changing environments is also critical to interpret Zheng's experiment where 67 out of 67 subclones obtained after isolation and expansion of single cells in serum containing media were able to induce tumors: Single cells expanded in serum free media did not form clones (but remained quiescent and viable) or formed clones with limited growth but, after shifting to serum containing media, both types of cells were able to form typical tumorigenic clones (Zheng et al., 2007). Thus, their data indicate that most C6 are "cancer stem cells" and the environment dictates the phenotype. One can assume that serum containing media favor proliferation of all cells that allows successful expansion of single cells generating phenotypic diversity in the expanded clonal culture. The phenotypic diversity we postulate is supported by the fact that a)
Clones formed from $\mathrm{CD} 133^{-}$single cells generate descendant having a mixture of $\mathrm{CD}_{133^{-}}$and $\mathrm{CD}^{\circ} 33^{+}$cells (Zheng et al., 2007). b) Both $\mathrm{CD}_{133}{ }^{-}$and $\mathrm{CD} 133^{+}$cells have also self renewal capacity (Chen et al., 2010; Kelly et al., 2009), c) non-SP cells can generate both SP and nonSP cells (Fong et al., 2010; Platet et al., 2007) apparently depending on the culture conditions since there are studies where non-SP cells only produce non-SP cells (Kondo et al., 2004). d) expression of CNS markers (GFAP, Nestin; and NES) vary with culture conditions (Prestegarden et al., 2010) providing strong in vitro experimental evidence that tumor microenvironment might be an important factor in determining the percentage of cells expressing certain stem cell marker and perhaps, affecting the stemness of the cell as our model suggest. Nestin has been used as a glioma stem cell marker (Table 1). Another line of evidence supporting our hypothesis comes from the existence of the "side population" (SP) in glioma cell lines. In several experiments, GSCs have been isolated from the SP cell fraction that has been found to vary between cell lines (Table 1) and it is thought that this fraction are stem cells (Fukaya et al., 2010). To persist, the SP fraction must have proliferation kinetic (e.g. PDT) equal or very similar to the rest of the cells present in the culture. Otherwise, it will either progressively disappear or outgrow the culture. The percentage of the SP fraction increased in serum free media containing both PDGF and bFGF but not in either PDGF or bFGF alone (Kondo et al., 2004). More important, both SP cells as well as non-SP cells can repopulate SP and non-SP cells (Fong et al., 2010; Platet et al., 2007). The SP

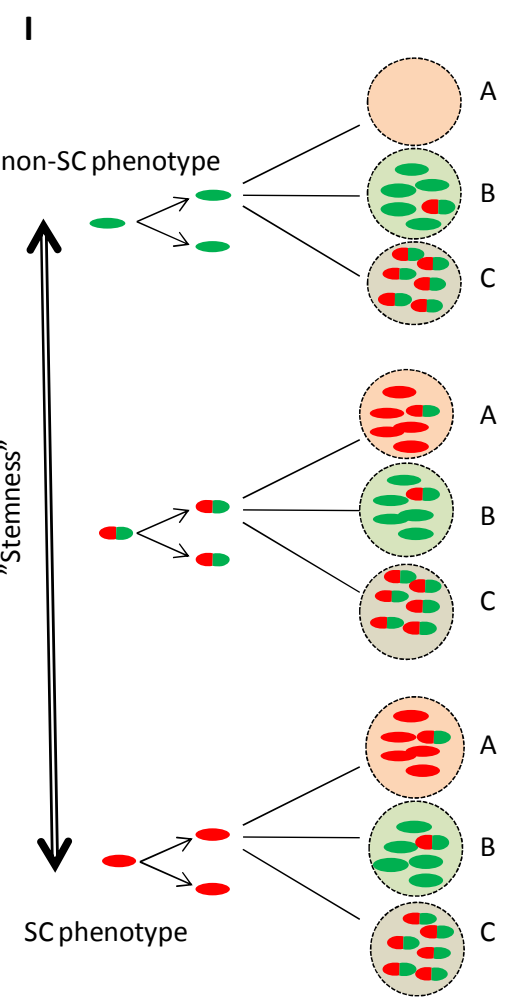

II

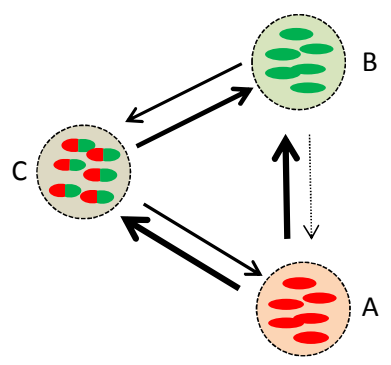

III

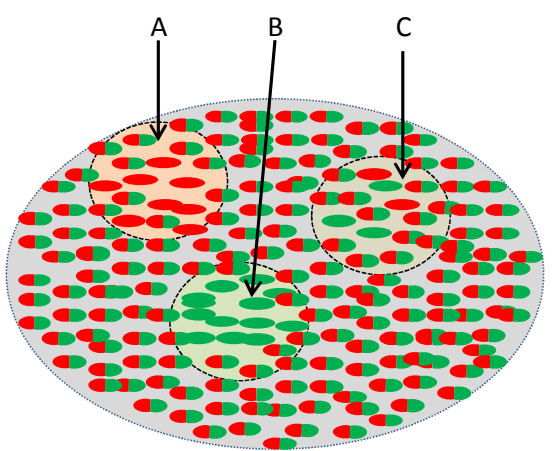

Figure 2: The Stemness phenotype model. I) All cancer cells have stem cell potential and divide symmetrically. Clonal expansion of a single cancer cell generates, due to random biological variation cells having different phenotypes ("stemness") ranging from a pure GSC phenotype (red oval) to a pure non-GSC phenotype (green oval) depending on the environment (e.g. A, B or C). Environment A represents an environment similar to stem cell media and B represents an environment similar to standard culture conditions. Environment $C$ represents an intermediate condition. II) In this example, three different phenotypes (pure SC, red ovals; pure non-SC, green ovals and an intermediate phenotype, red-green ovals) are represented in different "niches". All three phenotypes can potentially interconvert at variable degrees (arrows) into each phenotype when permissive changes in the microenvironment occur. III) In vivo, the percentage of each fraction depends on tumor microenvironments $(A, B, C)$ that might promote specific phenotypes. 
fraction from the SK-MG-1 cell line has greater proliferative ability $(\sim 10$ times) than non-SP cells when growing in neurosphere media containing EGF and FGF2 (Fukaya et al., 2010) clearly indicating that the SP phenotype is culture condition dependent. In our model, the SP population is simply a fraction of cells with higher stemness phenotype. When incubated in stem cell media (that might not be adequate for the rest of the cells) they survive and generate a cell line with stem-like properties. In conclusion the SPM explains why cell lines obtained from either single cell isolation (e.g. C6 cells) or mixed primary cultures produce cell lines with a mixture of phenotypes.

Finally, if we also assume that most cancers might originate from a single cell that becomes a cancer cell (Martínez-Climent et al., 2006), then models based in 2 or 3 compartments should explain not only the origin of each cell subpopulations but also their persistence in several cell lines. The stemloid hypothesis should explain the origin of each of the three cancer cell types: non-GSCs, GSC and stemloids. It is easy to imagine that a single cell may be responsible for the initial cancer and the different phenotypes arise as the tumor grows and create microenvironments favouring one or another phenotype. It is important to notice that the original C6 glioma cell line was isolated from a clonal strain (Benda et al., 1968) providing evidence that a single original tumoral cell was indeed a stem cell able to generate the different phenotypes (and subpopulations) present in the C6 cell line. In 2009, Gupta et al proposed a "plasticity model" enabling bidirectional interconvertibility between CSCs and non-CSCs (Gupta et al., 2009). Although at a first glance it seems very similar to ours, Gupta's model proposes a unidirectional hierarchy from stem cells to post-mitotic differentiated cells. This unidirectionality predicts that, contrary to Zhengs's experimental findings, a fraction of isolated single cells will not have stem cell properties. In our model, cancer cells can interconvert regardless of the phenotype providing that a permissive environment allows the transition (Figure 2II). In summary, our hypothesis provides an explanation to several controversial experimental data regarding the presence of GSCs in cell lines and provides and alternative way to reconciliate the cancer stem cell hypothesis.

\section{Stem cells in tumors}

The same analysis we used for cell lines can be extrapolated to this in vivo situation. While pure symmetrical division of a primordial stem cell predicts that any glioma in vivo should have $100 \%$ of GSCs, pure asymmetrical division will generate a tumor with only 1 GSC and increasing number of non-GSCs. Contrary to the situation in cell lines, the three possible models discussed above- GSCs that divides symmetrically + differentiation; GSCs that divides asymmetrically and symmetrically, (Figure 1, B and D) and the SPM (Figure 2) may occur in vivo because tumors in situ are not subjected to routine passages. All three models support the concept that a tumor can be originated from a single cell and produce cells with different phenotypes. However, the first two models by predicting the existence of non-GSCs, can't explain Zheng's experiments unless we assume 1) that only GSCs are able to propagate in vitro when establishing a cell line and 2) once the culture is expanded and non-GSCs appear either by differentiation of GSCs (Figure 1B) or spontaneous symmetrical division (Figure 1D), a very delicate balance exists to prevent the outgrowth of the faster cell subpopulation and maintain a low but constant fraction of GSCs. Instead, the SPM proposes that in vivo all glioma cells have stem cell properties but different stemness phenotype (but not true non-GSCs) depending on the microenvironment (Figure 2III).

Are all cancer cells in vivo stem cells? A key issue that need to be addressed in order to find which of the above mentioned models better explain what occurs in vivo is whether tumors always contain stem cells ("constant presence") or not ("variable presence") and what is the percentage (ranging between $>0-100 \%$ ) of stem cells in a given tumor that contains GSCs (e.g. "constant percentage" or "variable percentage"). At least six different situations can be account (A-F in Table S1). With few exceptions literature data provide evidence that cancer stem cells (CSCs) have been isolated from almost all gliomas specimens when they have searched for them (Table 3). The few negative results could be due to technical reasons (e.g. in some tumors, the cells cannot withstand the process required to generate a single-cell suspension for culturing) rather than a true lack of GSCs in the tumor. This strongly suggests that the presence of CSCs might be constant and excludes situations D-F limiting the possibilities to only three situations (A-C, Table S1). Consistent with situations $B$ or $C$, early studies detecting stem cell markers and/or isolating spheres from primary cultures showed that a relatively small percentage (no more than 25\%) is probably stem cells (Al-Hajj and Clarke, 2004; Yuan et al., 2004 ). The fact that CD133- cells can give origin to both $\mathrm{CD}_{133^{-}}$and $\mathrm{CD}^{-133^{+}}$cells (Zheng et al., 2007) and the recent finding that $\mathrm{CD} 133^{\circ}$ cells express a truncated variant of the CD133 protein not recognized by some antibodies (Osmond et al., 2010) makes this approach unreliable. The use of the SP or Nestin as specific stem cell markers for isolating/detecting GSCs in tumors are also unreliable (See above). If we consider the increasing evidence that the non-SP fraction and CD133 cells, can generate the

\begin{tabular}{|c|c|c|c|}
\hline Study & Criteria to define CSCs & Percentage (n) & Pathological subtype \\
\hline (Ignatova et al., 2002) & Isolation of clonogenic cells & $80 \%(n=10)$ & $\begin{array}{l}\text { Anaplastic astrocytoma } \\
\text { and recurrent malignant GBM }\end{array}$ \\
\hline (Brehar et al., 2009) & $\begin{array}{l}\text { Expression of stem cell markers (nestin, } \\
\text { CD133) }\end{array}$ & $100 \%(n=1)$ & Glioblastoma (1) \\
\hline (Galli et al., 2004) & $\begin{array}{l}\text { capacity for long-term proliferation, self- } \\
\text { renewal, multipotency and their } \\
\text { tumorigenicity }\end{array}$ & $100 \%(n=10)$ & Glioblastoma (6), Medulloblastoma (4), \\
\hline (Singh et al., 2003) & $\begin{array}{c}\text { Self-renewal, proliferation, and lineage } \\
\text { restricted } \\
\text { differentiation }\end{array}$ & $100 \%(n=14)$ & $\begin{array}{c}\text { Medulloblastoma (8), Pilocytic astrocytoma (3), } \\
\text { Grade } 2 \text { astrocytoma (1), Ependymoma (1), } \\
\text { Ganglioglioma (1) }\end{array}$ \\
\hline (Yuan et al., 2004 ) & $\begin{array}{l}\text { Formation of tumor spheres, self-renewal } \\
\text { capacitiy, expression of } \\
\text { NSC markers as well as lineage markers, } \\
\text { multipotentiality, capability of forming } \\
\text { tumors in vivo }\end{array}$ & $100 \%(n=6)$ & Glioblastomas \\
\hline (Bao et al., 2006) & Neurosphere formation and tumorigencity & $100 \%(n=3)$ & Primary gliomas \\
\hline (Yi et al., 2007) & Formation of tumor spheres, Tumorigenicity & $100 \%(n=3)$ & anaplastic oligoastrocytoma \\
\hline (Kelly et al., 2009) & $\begin{array}{l}\text { Formation of tumor spheres, self-renewal } \\
\text { capacitiy, multilineage Differentiation }\end{array}$ & $73 \%(n=11)$ & Glioblastomas \\
\hline
\end{tabular}

Table 3: Isolation of cancer stem cells from human brain tumors. With few exceptions, cancer stem cells has been isolated from $100 \%$ of all tumors. 
SP fraction and $\mathrm{CD}_{133^{+}}$cells respectively, the natural conclusion is that not only the SP fraction or $\mathrm{CD} 133^{+}$cells but all glioma cells might have stem cell properties. Therefore, at present the growing experimental evidence favours a model where tumors have "constant presence" and "constant percentage $=100 \%$ " (situation A in Table S1) that fits the SPM. The two other models (Figure $1 \mathrm{~B}$ and D) do not explain this situation because they predict the existence of non-stem cells. The model in Figure 1B (without assuming that a fraction of GSCs "differentiate" producing non-GSCs (box), by predicting that all the progeny are the same, do not explain the different phenotypes (degree of stemness) found in tumors. The ideal experiment to address this key issue should be by isolating single cells from a huge numbers of fresh glioma tumors, and by determination of the percentage of the number of clones having stem cell properties. It is expected that if the tumor is a mixture of GSCs and non-GSCs a certain number of clonal lines will proliferate but they will never have stem cell properties. The main concern is that non-GSC might not survive the hard condition required to propagate single cells. The number of isolated single cells that do not proliferate in vitro might be informative to address this concern. In addition, isolated single cells can be grown in different culture media that might promote non-GSCs growth and overcome this limitation.

Experimental data already provide evidence supporting the idea that a single cell with stem cell properties can originate a new tumor in vivo and rule out the need of two or more different subpopulations for tumor growth. Thus, it is also likely that tumors in vivo originate from a single cell (stem cell, stem-like cell or non-GSC that mutated and acquired stem cell properties by reactivating latent stem cell program (Nicolis, 2007) and all the descendants are indeed cells having stem cell properties but very different phenotype due to microenvironmental tumor heterogeneity such as perivascular niches that migh promote stemness (Charles et al., 2010).

\section{Implications of the SP model}

As discussed above, the original hope that killing GSCs will eradicate the tumor has been challenged by the fact that surviving non-GSC might be able to induce tumor relapse because the Hayflick limit is not a barrier for preventing symptomatic tumoral masses (Hanahan and Weinberg, 2000; Withers and Lee, 2006). All models predict that survival of a single cell might induce tumor relapse. Since models B and D in Figure 1 predict that non-GSCs are being generated constantly, these newly formed cells are at early stage of the Hayflick limit (approximately 60-70 divisions) and able to divide enough number of times to generate a tumor mass responsible for symptoms. It is estimated that the volume of $1 \times 10^{9}$ cells (the result of 30 divisions from a single cell) will produce a tumor volume of approximately 1 $\mathrm{ml}$ (Withers and Lee, 2006) and 60-70 divisions can in theory produce large tumoral masses (Hanahan and Weinberg, 2000). Targeting specific cell subpopulation based on stem cell markers (e.g. CD133+) is also unlikely to be successful because cells lacking a specific stem cell marker can also produce (by inter conversion) descendants with stem cell properties. From the clinical point of view, if true, the SPM will change the strategy for finding new therapeutic strategies at the preclinical level. Instead of isolating SP cells or $\mathrm{CD}_{133^{+}}$cells from a cell line as source of stem cells to identify vulnerabilities, it might be equally or even more informative, to analyse established glioma cell lines or patient derived cell lines growing in different culture conditions that generates different phenotypes resembling in vivo microenvironments such as hypoxic regions (Heddleston et al., 2009; Kim et al., 2009; Seidel et al., 2010) or perivascular niches (Charles et al., 2010) that contributes to the maintenance of stemness. It might also be more successful to design therapies that kill all glioma cells in such environments than to identify a potential specific stem cell killer agent that will only kill a subpopulation of cells having a particular stemness phenotype.

\section{Funding}

This work was supported by grants from the Swedish Research Council and the Karolinska Institute.

\section{References}

1. Al-Hajj M, Clarke MF (2004) Self-renewal and solid tumor stem cells. Oncogene 23: 7274-7282.

2. Bao S, Wu Q, McLendon RE, Hao Y, Shi Q, et al. (2006) Glioma stem cells promote radioresistance by preferential activation of the DNA damage response. Nature 444: 756-760.

3. Benda P, Lightbody J, Sato G, Levine L, Sweet W (1968) Differentiated rat glial cell strain in tissue culture. Science 161: 370-371.

4. Bexell D, Gunnarsson S, Siesjö P, Bengzon J, Darabi A (2009) CD133+ and nestin+ tumor-initiating cells dominate in N29 and N32 experimental gliomas. Int J Cancer 125: 15-22.

5. Blagosklonny MV (2007) Cancer stem cell and cancer stemloids: from biology to therapy. Cancer Biol Ther 6: 1684-1690.

6. Brehar FM, Bleotu C, Stefan LM, Buzgariu W, Chivu M, et al. (2009) Isolation and partial characterization of a new human glioblastoma cell line. Chirurgia (Bucur) 104: 453-461.

7. Charles N, Ozawa T, Squatrito M, Bleau AM, Brennan CW, et al. (2010) Perivascular nitric oxide activates notch signaling and promotes stem-like character in PDGF-induced glioma cells. Cell Stem Cell 6: 141-152.

8. Charles NA, Holland EC (2010) TRRAP and the maintenance of stemness in gliomas. Cell Stem Cell 6: 6-7.

9. Chen R, Nishimura MC, Bumbaca SM, Kharbanda S, Forrest WF, et al. (2010) A hierarchy of self-renewing tumor-initiating cell types in glioblastoma. Cancer Cell 17: 362-375.

10. Chua C, Zaiden N, Chong KH, See SJ, Wong MC, et al. (2008) Characterization of a side population of astrocytoma cells in response to temozolomide. J Neurosurg 109: 856-866

11. Fong D, Yeh A, Naftalovich R, Choi TH, Chan MM (2010) Curcumin inhibits the side population (SP) phenotype of the rat $\mathrm{C} 6$ glioma cell line: Towards targeting of cancer stem cells with phytochemicals. Cancer Lett 293: 65-72.

12. Fukaya R, Ohta S, Yamaguchi M, Fujii H, Kawakami $Y$, et al. (2010) Isolation of cancer stem-like cells from a side population of a human glioblastoma cell line, SK-MG-1. Cancer Lett 291: 150-157.

13. Galli R, Binda E, Orfanelli U, Cipelletti B, Gritti A, et al. (2004) Isolation and characterization of tumorigenic, stem-like neural precursors from human glioblastoma. Cancer Res 64: 7011-7021.

14. Griguer CE, Oliva CR, Gobin E, Marcorelles P, Benos DJ, et al. (2008) CD133 is a marker of bioenergetic stress in human glioma. PLoS ONE 3: e3655.

15. Gupta PB, Chaffer CL, Weinberg RA (2009) Cancer stem cells: mirage or reality? Nat Med 15: 1010-1012.

16. Hanahan D, Weinberg RA (2000) The hallmarks of cancer. Cell 100: 57-70.

17. Heddleston JM, Li Z, McLendon RE, Hjelmeland AB, Rich JN (2009) The hypoxic microenvironment maintains glioblastoma stem cells and promotes reprogramming towards a cancer stem cell phenotype. Cell Cycle 8: 3274 3284.

18. Hill RP (2006) Identifying cancer stem cells in solid tumors: case not proven. Cancer Res 66: 1891-1895.

19. Ignatova TN, Kukekov VG, Laywell ED, Suslov ON, Vrionis FD, et al. (2002) Human cortical glial tumors contain neural stem-like cells expressing astroglial and neuronal markers in vitro. Glia 39: 193-206.

20. Kelly JJ, Stechishin O, Chojnacki A, Lun X, Sun B, et al. (2009) Proliferation of human glioblastoma stem cells occurs independently of exogenous mitogens. Stem Cells 27: 1722-1733.

21. Kim Y, Lin Q, Zelterman D, Yun Z (2009) Hypoxia-regulated delta-like 1 
homologue enhances cancer cell stemness and tumorigenicity. Cancer Res 69: 9271-9280

22. Kondo T, Setoguchi T, Taga T (2004) Persistence of a small subpopulation of cancer stem-like cells in the C6 glioma cell line. Proc Natl Acad Sci USA 101: 781-786.

23. Leychkis Y, Munzer SR, Richardson JL (2009) What is stemness? Stud Hist Philos Biol Biomed Sci 40: 312-320.

24. Martínez-Climent JA, Andreu EJ, Prosper F (2006) Somatic stem cells and the origin of cancer. Clin Transl Oncol 8: 647-663.

25. McBride S, Meleady P, Baird A, Dinsdale D, Clynes M (1998) Human lung carcinoma cell line DLKP contains 3 distinct subpopulations with differen growth and attachment properties. Tumor Biol 19: 88-103.

26. McCord AM, Jamal M, Williams ES, Camphausen K, Tofilon PJ (2009) CD133+ glioblastoma stem-like cells are radiosensitive with a defective DNA damage response compared with established cell lines. Clin Cancer Res 15: 51455153.

27. Nicolis SK (2007) Cancer stem cells and "stemness" genes in neuro-oncology. Neurobiol Dis 25: 217-229.

28. Osmond TL, Broadley KW, McConnell MJ (2010) Glioblastoma cells negative for the anti-CD133 antibody AC133 express a truncated variant of the CD133 protein. Int J Mol Med 25: 883-888.

29. Platet N, Mayol JF, Berger F, Hérodin F, Wion D (2007) Fluctuation of the SP/ non-SP phenotype in the C6 glioma cell line. FEBS Lett 581: 1435-1440.

30. Prestegarden L, Svendsen A, Wang J, Sleire L, Skaftnesmo KO, et al. (2010) Glioma cell populations grouped by different cell type markers drive brain tumor growth. Cancer Res 70: 4274-4279.

31. Qiang L, Yang Y, Ma YJ, Chen FH, Zhang LB, et al. (2009) Isolation and characterization of cancer stem like cells in human glioblastoma cell lines. Cancer Lett 279: 13-21.

32. Ropolo M, Daga A, Griffero F, Foresta M, Casartelli G, et al. (2009) Comparative analysis of DNA repair in stem and nonstem glioma cell cultures. Mol Cancer Res 7: 383-392.
33. Rubin $H$ (2002) The disparity between human cell senescence in vitro and lifelong replication in vivo. Nat Biotechnol 20: 675-681.

34. Seidel S, Garvalov BK, Wirta V, von Stechow L, Schänzer A, et al. (2010) A hypoxic niche regulates glioblastoma stem cells through hypoxia inducible factor 2 alpha. Brain 133: 983-995.

35. Setoguchi T, Taga T, Kondo T (2004) Cancer stem cells persist in many cancer cell lines. Cell Cycle 3: 414-415.

36. Shen G, Shen F, Shi Z, Liu W, Hu W, et al. (2008) Identification of cancer stemlike cells in the $\mathrm{C} 6$ glioma cell line and the limitation of current identification methods. In Vitro Cell Dev Biol Anim 44: 280-289.

37. Singh SK, Clarke ID, Terasaki M, Bonn VE, Hawkins C, et al. (2003) Identification of a cancer stem cell in human brain tumors. Cancer Res 63: 5821-5828.

38. Singh SK, Hawkins C, Clarke ID, Squire JA, Bayani J, et al. (2004) Identification of human brain tumor initiating cells. Nature 432: 396-401.

39. Soeda A, Park M, Lee D, Mintz A, Androutsellis-Theotokis A, et al. (2009) Hypoxia promotes expansion of the CD133-positive glioma stem cells through activation of HIF-1alpha. Oncogene 28: 3949-3959.

40. Withers HR, Lee SP (2006) Modeling growth kinetics and statistical distribution of oligometastases. Semin Radiat Oncol 16: 111-119.

41. Yakisich JS (2009) Theoretical basis for the measurement of small differences in the length of the cell cycle between two cell populations. The Open Biology Journal 2: 95-100.

42. Yi L, Zhou ZH, Ping YF, Chen JH, Yao XH (2007) Isolation and characterization of stem cell-like precursor cells from primary human anaplastic oligoastrocytoma. Mod Pathol 20: 1061-1068.

43. Yuan X, Curtin J, Xiong Y, Liu G, Waschsmann-Hogiu S, et al. (2004) Isolation of cancer stem cells from adult glioblastoma multiforme. Oncogene 23: 9392 9400

44. Zheng X, Shen G, Yang X, Liu W (2007) Most C6 cells are cancer stem cells: evidence from clonal and population analyses. Cancer Res 67: 3691-3697.

45. Zhou XD, Wang XY, Qu FJ, Zhong YH, Lu XD, et al. (2009) Detection of cancer stem cells from the C6 glioma cell line. J Int Med Res 37: 503-510. 